\title{
Indicators and metrics for social business: A review of current approaches
}

\author{
Arena Marika, Azzone Giovanni, Bengo Irene, Calderini Mario
}

Department of Management, Economics and Industrial Engineering Politecnico di Milano

\begin{abstract}
This paper aims to perform a review of different accounting frameworks, including indicators and metrics applicable to the social business sector, discussing the strengths and the weaknesses of different approaches in relationship to their ability to respond to objectives and interests of different stakeholders in the social business ecosystem. Then, the paper discusses the key role that indicators and metrics could play in the light of the transformations that the social business sector is witnessing, such as the emergence of new financial supply chains and the entrance of new relevant players.
\end{abstract}

Keywords: social business, social accounting, metrics and indicators, stakeholders, information needs 


\section{Introduction}

In the last decade, relevant social problems started to seriously afflict the so-called developed economies, challenging policy makers at the international level. The worldwide financial crisis has dampened the world economy, generating problems of financial sustainability to private and public organizations (Sgherri and Zoli 2009; Reinhart and Rogoff 2010). The governments in many countries had to face critical issues such as a general decrease of families' income, growing level of unemployment especially for vulnerable groups (such as women, youth, immigrants), need of cutting social programs (like education, health care, work benefits) to preserve financial sustainability (Vis et al. 2011; Karanikolos et al. 2013). At the same time, the situation has not improved for developing countries, that still face huge social problems such as economic poverty, hunger, unsafe water supplies, poor education systems, poor sanitation (Brinkman et al. 2009; OECD 2014; Santos 2012; Seelos and Mair 2005; World Bank 2003).

One of the options that have been proposed to tackle these challenges is represented by social business, that has been defined as a market based arrangement whose primarily focus is on the pursuit of social and environmental objectives, however, ensuring, at least, the reimbursement of the investment (Austin, Stevenson, and Wei-Skillern 2006; Yunus 2007; Yunus et al. 2010). In this respect, social business is conceived as a new form of entrepreneurial initiative that joins the social purpose traditionally associated to the not for profit sector with the creation of economic value traditionally associated to for profit organizations (Wilson and Post 2013; Auerswald 2009; Leadbeter 2007; Alter 2006; Austin, Stevenson, and Wei-Skillern 2006).

This idea has attracted the attention of many different players in the economic system since there is some preliminary evidence that's social business initiatives can actually pay off, socially and financially (Wilson and Post 2013; Karamchandani, Kubzansky and Frandano 2009; Freireich and Fulton 2009). On the one hand, new forms of organizations with the specific aim of developing social business - i.e. the so called Social Enterprises - emerged and grew rapidly in numbers. According to the European Commission, the social economy includes 2 million enterprises (i.e., $10 \%$ of all European businesses) and employs over 14.5 million employees (i.e., $6,5 \%$ of working population of the EU-27 and about $7.4 \%$ in EU-15 countries) (European Commission 2013).

On the other hand, also profit and not for profit organizations started to find a potential role in social business. The former, in fact, saw the opportunity to invest in social business, as a possible way to exploit new synergies between financial and social performances and to redefine their corporate social responsibility strategies (Crowther and Reis 2011; Sinkovics et al. 2014). The latter recognized the ability of social business of dealing effectively with the social problems, being more sustainable in financial terms (Santos 2012; Seelos and Mair 2005). 
Despite the enthusiasm raised by its origin, social business initiatives still struggle to survive and grow, because they have to deal with a progressive reconfiguration that is taking place in the social business ecosystem that requires a change of mindset from the operators as well as the adoption of new managerial tools. In many countries, in fact, the social sector is witnessing to the rise of new financial supply chains that play a crucial role in funding the provision of social services (and, therefore, the organizations implicated in it). This new scenario is characterized by the presence of new actors, such as new financial intermediaries (Grabenwarted and Liechtenstein 2012; Bugg-Levine and Emerson 2011), public actors that are changing their procurement practices (Sethi 2005; Achleitner et al. 2011), social impact investors (Jansson and Biel 2011; Chan et al. 2010; Glänzel, Schmitz, and Mildenberger 2012), that are those that now fund social service providers in a consistent way. This reconfiguration obviously requires the organizations that wants to operate in the social business to pay attention to their "revenues stream", and understand how to increase it building a cooperative relationship with the above actors.

Concerning this issue, different authors identified the poor understanding of value generated amongst the stakeholders and the rise of tensions and conflicts in meeting both the financial and the social bottom line as critical barriers to the growth of the social business sector (Bull and Crompton 2006; Marks and Hunter 2007; Nicholls, 2010a). In order to capture this value and demonstrate the impact of social business organizations, accounting frameworks are needed, for supporting the communication and the interaction between all the actors. Though this problem is not new in the accounting literature - since it has been addressed in the field of social accounting (Mathews 1997; Richmond, Mook and Quarter 2003) - a consolidated framework consistent with social business specific characteristics is still missing (EU 2014; Arena, Azzone, and Bengo 2015; Sacks 2002).

The lack of a recognized accounting framework with credible indicators and metrics is seriously limiting the capacity of social business organizations to compete in this new socio-economic scenario at different levels. First, it limits the ability of social business organizations to attract investments and donations, since potential investors / donors do not have reliable and recognized instruments to evaluate the potential and the results of their investment and compare them against other investment options (Marks and Hunter 2007; Plotnieks 2014). Second, the lack of shared indicators and metrics limits the possibility for social business organizations to obtain policy makers' support, because policy makers struggle to evaluate the impact of social business projects and activities on both the society and public finance (Paton 2003; Saltuk 2014). Finally, it limits the ability of the managers themselves in planning and controlling their operational activities and communicating with the broad range of stakeholders (Nicholls 2009; Alexander, Brudney, and Yang 2010).

To address this problem, this paper aims to perform a review of different accounting frameworks, indicators and metrics applicable to the social business sector, discussing the strengths and the weaknesses of different approaches in connection to their ability to respond to objectives and information needs of different 
stakeholders. To this aim, the paper positions the problem of measuring social business performance in the social accounting discourse, and analyses what are the main stakeholders' objectives and informative needs in the field of social business. Then it reviews the state of the art literature concerning indicators and metrics for measuring social business results, to show how these instruments are developing and discuss which areas could be improved in order to address the interests of different stakeholders.

The rest of the paper is articulated as follows. Section two presents the research framework, section three outlines the information needs of different stakeholders; section four presents the research method; section five presents the results of the literature review. Then, section six discusses the research finding and concludes with a possible agenda for future research.

\section{Social accounting and social business}

In the field of Social Accounting, researchers already addressed the problem of the pervasive role of the system of stakeholders and their multi-dimensional interests in informing accounting mechanisms.

Social accounting has its origins in the early 1970s, when it was referred to as either environmental accounting or social and environmental accounting, reflecting its concerns with the impact of the organization on the natural environment (Bebbington et al. 1999, Gray et al. 1996, Mathews 1997). Gradually, the emphasis on the environmental impact has shifted to a broader range of social concerns as it is highlighted in a recent definition of social accounting as "a systematic analysis of the effects of an organization on its communities of interest or stakeholders, with stakeholder input as part of the data that are analyzed for the accounting statement"' (Mook and Quarter 2003).

Social accounting is based on the idea of integrating the information needs of different stakeholders and balancing their different social and economic objectives (Gray 2002; Mathews 2004). Based on the theoretical foundation of social constructivism, stakeholders are seen as a key players in the construction of the organization itself (Gray 1997), reflecting the interaction between the organization and its environs (Guba and Lincoln, 1989). Social accounting reflects the "core values" of the organization, which, in turns, reflects the core values of stakeholders. Hence social accounting mirrors the interests of stakeholders (Wendt 1999; Nicholls, 2010b), synthetizing the views of different actors and balancing or negotiating between competing interests and expectations (Sefton, 2000).

In this process of reciprocal influence, a stakeholder can be privileged compared to others, by influencing even more the aforementioned interplay. From this perspective, social accounting might become a sort of "public relations tool" which is adopted to win (or maintain) the approval of those stakeholders whose continued support is crucial for the perceived legitimacy of an organization's activities (Bebbington, Unerman, and O'Dwyer 2014; Bebbington and Gray 2001). If this is the case, practices of social accounting 
might be perceived as addressing the interests of the most powerful stakeholders, while marginalizing the interests and needs of less powerful ones.

Moving from these premises, the analysis of social accounting literature highlights the coexistence of three different problems that are particularly relevant in the field of social business.

The first is an issue referring to the multi-stakeholder orientation of social accounting, which requires a definition of "social account" - i.e. the account of corporate activity containing a combination of financial and nonfinancial information - based upon the views of different stakeholders (Gray 2000). Social accounting scholars discuss the need of empowering the broadest range of stakeholder through stakeholder engagement (O'Dwyer 2005, Gray 2002, Thomson \& Bebbington 2005), and advance the ideals of stakeholder representativeness and influence extending the accountability and transparency of organisations (Lehman 1995, Owen and Swift 2001).

The second problem is explained by different stakeholders having different and sometimes contrasting objectives; based on these objectives they have also different information needs (Wilson 2014; Richmond, Mook and Quarter 2003; Preston and Donaldson 1995). Hence, an organization should map different stakeholders' expectations, objectives and interests, in order to develop a different set of possible metrics (Herman and Renz, 1997; Fletcher et al. 2003) and reduce the asymmetries between the organisation and its stakeholders (Gray et al. 1997, Gao and Zhang 2006).

Finally, any system of social accounting has the potential of transferring power from one stakeholder to another (EC 2014) and from an organization to its stakeholders (Freeman 1994, Donaldson 1995, Friedman 2002, Richmond, Mook and Quarter 2003). The information flow influences and is influenced by the balance of powers among the actors (the power of parties to demand it and/or the willingness/desire of an organisation to provide it Stone 1975; Gray et al. 1997). This balance between powers also interacts with law or quasi-law processes (Gray 2001) that, under some circumstances, might influence the information flows in different ways (for instance by setting some minimum requirements).

All these three issues are particularly relevant in connection to social business, which is characterized by a complex stakeholders' system where different actors can easily have contrasting objectives. Furthermore, the balance of power between different actors is very fluid, since the regulatory framework is still fragmented and the system of values of social business ecosystems are constantly evolving. Hence, the problem of identifying what accounting frameworks are more suitable to answer social business specific features appears particularly relevant and is derived by an analysis of the interests of different groups of stakeholders (Nicholls 2009). 
Moving from these considerations, the next section maps the interests of the main groups of stakeholders while section four analyses the existing accounting frameworks, indicators and metrics used to measure SB values and underlining as these approaches respond to the stakeholders needs.

\section{The stakeholders' information needs}

In this section, the paper discusses different information needs associated to three broad categories of stakeholders /actors that play a significant role in the "social business ecosystem": different types of funders (including investors and other funders like charities, foundations); policy makers and decision makers in social business organizations. As follows, are analysed the stakeholders' interests based on the idea that when choosing any metrics or developing a new one, it is important to take into account what purpose these metrics will serve (Plotnieks 2014).

The first category of stakeholders includes different social business funders distinguishing between private/institutional investors and grant-makers (charities, foundations...). The private and institutional investors put resources in a social business initiative in order to obtain a financial and a social return (BuggLevine and Emerson 2011; Hebb 2013; Jackson 2013). Hence, investors in social business should be able to recognize the financial and social impact determined by their investments. To this aim, traditional approaches tend to underestimate the return of an investment in social business, since the contribution to social value creation is disregarded by traditional financial markets, though it is generally recognized that the socio-economic development leads the financial growth. In the case of social business, an investment's pay off is, in fact, constituted by two components - the financial and the social one - however only the former is actually quantified and used to compare the investment returns against those associated by different asset classes. This situation leads to the need embracing approaches that could better capture the impact produced by a social business organization in both social and financial terms. The grant-makers, on the other hand, have different interests, since the financial return from grants is by definition zero. Hence, this type of funders generally wish to measure the social impact achieved by a social business organization and the cost for achieving that impact in order to compare the performance of a specific initiative with different projects / initiatives pursuing similar goals. (Chan et al. 2009).

The second category of stakeholders includes policy makers (such as central governments and international policy bodies). Policy makers have an articulated relationship with social business organizations. On the one hand, they are up to define policies that could (or could not) support social business initiatives (Saltuk 2014). Governments, for instance, can create an environment favorable to social entrepreneurship (Paton 2003), by defining rules and regulations that simplify business operations for social business organization. Furthermore, public support is essential in building community awareness and trust in connection to social business (Korosec and Berman 2006). From this perspective, policy makers need indicators and metrics to assess the potential contribution of social business and evaluate the impact of these policies for communities 
and citizens, and the central government. On the other hand, central Governments can finance social business organizations directly, by subcontracting some social services or participating as a partner in carrying out a social program. From this perspective, they have to be able to evaluate the results of the subcontracting organizations in term of the services quality and demonstrate the impact generated by social programs that have been developed (SEC 2011; Hyndman and McMahon 2011; G8 2014).

Finally, the third category of stakeholders includes decision makers in social business organizations which could be a social entrepreneur or other managers (henceforth decision makers). For these actors, the achievement of the social mission is clearly the heart of a social business initiative and it passes through the management of day by day operations (Ormiston and Seymour 2011). To achieve their social mission, decision makers need to monitor how operations are run, understand how to improve effectiveness in the service delivery, monitor the social impact, and interact and communicate with all the above stakeholders. From this perspective, they need indicators and metrics to support internal decision making processes, guide their choices and improve effectiveness and efficiency of business operations. Furthermore, indicators and metrics could enhance accountability and support the achievement of legitimacy with the broad range of stakeholders (Dart and Grant 2004; Kendall and Knapp 2000a; Paton 2003; Alexander, Brudney, and Yang 2010).

\section{Research method}

To map instruments currently used to define a indicators and metrics for social business a scoping literature review was performed (Arksey and O'Malley 2005). This approach was selected because it is considered particularly suitable when the review is aimed to outline the current state of the art in an area of interest, that cannot be closely defined, and identify gaps where further research is required. The scoping review may be contrasted with the systematic review, because the latter is more restricted in focus: the systematic review aims to provide answers to questions from a relatively narrow range of quality assessed studies, whilst a scoping study is less likely to seek to address very specific research questions nor to assess the quality of included studies (Arksey and O'Malley 2005).

These characteristics of a scoping literature review are coherent with the features of the area under investigation: social business per se is a dynamic and fuzzy concept (Peredo et al. 2006) and many approaches to social business performance measurement have originated in different disciplines / fields, such as management accounting, operations management, social responsibility and sustainability, and have been then "borrowed" and adapted in more recent literature dealing with not for profit sector and international cooperation, social enterprise and social business, impact finance and impact investing (G8 2014). Furthermore, some models and approaches have originated in the practice, being only later formalized from a theoretical perspective (Hornsby 2012) 
Moving from these considerations, the scoping review was performed following the protocol suggested by Arksey and O'Malley (2005), that consists of five steps: (1) identifying the questions; (2) identifying relevant literature; (3) selecting the literature; (4) charting the data; and (5) collating, summarizing and reporting the results (see Table 1 for details).

[Please Insert Table 1 here]

The approaches highlighted by the literature review were categorized into three groups of contributions (see Figure 1). The first group, synthetic indicators, includes models that leads to the construction of a synthetic indicator aimed to measure social value creation. The second group of contributions, process based approaches, includes models that focus on the process of "production" of a social service / product, articulating the analysis of social business performance in inputs-outputs-outcomes and impacts. Finally the third group, dashboards and scorecards, includes models aimed to provide a picture of the results of an organization aimed to social business, according to different performance dimensions, that are considered representative of the results of the organization.

[Please Insert Figure 1 here]

\section{Results of the review}

Different contributions were organized into three groups, based on the key characteristics of the analysed approaches / frameworks. As follows, the three streams of references are presented, highlighting the context in which these approaches originated (e.g. not for profit organization, or social enterprises, or impact finance initiatives) and the key similarities and differences in the proposed approaches, as well as their main contribution in terms of ability to define indicators and metrics.

\subsection{Synthetic measures}

The first group of models includes approaches that lead to the calculation of a synthetic indicator/metrics to provide a measure of the global performance of a social organization.

These approaches focus on the final outcome of a social business organizations, even if some of them take their move from inputs-outputs-outcomes models (NEF 2007) or, more in general, from the process of value 
creation by social business (Sacks 2002; Grabenwarter and Liechtenstein 2011). At any rate, the final result is a synthetic indicator /metric of the value created from an economic, environmental and social perspective.

Among these models, the most famous is SROI, developed by the Roberts Enterprise Development Fund (REDF) for social enterprises and tested by the New Economics Foundation (NEF) in 2007. SROI is defined as a form of adjusted cost-benefit analysis that takes into account, in a more holistic way, different types of impacts that social programmes may determine (Lawlor 2009). Like more traditional cost-benefit analysis, SROI combines the discounted cash flows associated to benefits and costs related to a certain activity over a certain period of time (Lyon et al. 2010). In particular, it is defined by the following formula:

SROI $=$ Net Present Value of Benefits/ Net Present Value of Investment

Hence, it requires to review and synthesize the inputs, outputs, outcomes and impacts made and experienced by the stakeholders of an organization in relation to its activities, and assigning a monetary value to social, economic and environmental benefits and costs created by an organisation. SROI measurement should be matched by qualitative evidence based on stakeholder inquiry, wherein the stakeholder is defined as 'people or organisations that experience change, whether positive or negative, as a result of the activity being analysed (Nicholls et al. 2009).

In order to estimate the positive (or negative) social value of non-traded, nonmarket goods the use of financial proxies is the main attraction in deciding to use the SROI approach (Flockhart 2005). SROI measures the value of social benefits created by an organisation, in relation to the relative cost of achieving those benefits (Rotheroe and Richards 2007).

A further synthetic indicator is the Local Multiplier 3 (LM 3) developed by Sacks (2002) for NEF. LM3 is based on the concept that an economic multiplier effect describes the impact that spending has in the economy, taking into consideration the knock-on effects. The "multiplier" is an economic concept: a higher proportion of money re-spent in the local economy means a higher multiplier effect because more income is generated for local people. More income retained locally, or nationally, means more jobs, higher pay and more tax revenue for government, all of which may lead to better living standards. The measuring process is articulated into three steps: (1) identifying a source of income, (2) following how it is spent and (3) following how it is re-spent within a defined geographic area (local economy).

Finally, Grabenwarter and Liechtenstein (2011) propose the Gamma Model, that originates in the social impact investing field with the aim to design a system to define a synthetic indicator to measure social or environmental impacts consistently with the financial market standards. The model grounds in the capital asset pricing model (CAPM) and integrates the concept of social and/or environmental impact into an investment's overall return equation, deriving the gamma factor, that is a synthetic measure of the value created by an impact investment. In particular, the model splits the impact metrics into the impact objectives 
at investment level as indicators performance indicators (KPIs) and the performance of investment through an "impact-adjusted return". Then, it proposes the use of impact performance indicators as input factors for impact investment performance indicators, i.e. the impact performance indicators, from the point of view of manager, express the quality of investment selection decisions based on the impact performance. In this way, it defines an integrated measure for financial and impact-investing performance at portfolio level respecting the freedom for meaningful KPIs for the individual organizations.

\subsection{Process based models}

The second group of models focuses on the process of "production" of a social service / product, articulating indicators and metrics into inputs-outputs-outcomes and impacts.

This stream of literature originates in the public sector, where public administrations performances are usually assessed through the so-called three Es framework: economy, efficiency, and effectiveness, based upon an input, output, and outcome model (Flynn 1997; Rose, 1999; Carter, Klein, and Day 1995; Perrin 1998; Smith 1995; Heinrich 2002). In recent years, a few authors adapted and applied these models to social business, following the process through which an organization's activities lead to the organization's outcome and impact, articulating the relationship between the activities, outputs, outcomes, and impacts along the so-called impact chain of a social-purpose organization (Olsen and Galimidi 2008; GSVC 2012; Hornsby and Blumberg 2013).

All these models are articulated as a guideline to develop a set of indicators/metrics, however, some of them focus on the identification of the performance dimensions (Ebrahim and Rangan 2010), whilst other models also provide a guideline to select or build the KPIs based on internal and external factors (Bagnoli and Megali 2011; Hornsby 2012; GSVC 2012; Arena, Azzone, and Bengo 2014).

The first group of contributions includes models that focus on the definition of the performance dimensions that should be considered to cover the impact chain, however, without defining a set of indicators in operational terms (Ebrahim and Rangan 2010).

Ebrahim and Rangan (2010) propose a contingency framework that specifically aims at measuring performance in social sector organizations, monitoring how organizational inputs and activities lead to outputs, outcomes, and, societal impacts. In particular, the authors suggest that, given the variety of work, aims, and capacities of social sector organizations, some organizations should measure long-term impacts, while others should stick to measure shorter-term results. Hence, they propose an approach for determining which kinds of KPIs are appropriate, as driven by the mission and goals of the organization, but do not formalize the set of indicators/metrics in a pre-defined system. 
The second stream, composed by models that define both the performance dimensions and a set of KPIs, starts with Bagnoli and Megali (2011) that propose a multidimensional control system that constructs a map of indicators to measure social enterprise performance. The model is articulated into three performance dimensions: economic and financial performance, social effectiveness and institutional legitimacy. In particular, social effectiveness is defined in terms of compliance with the social mission of a social enterprise. Moreover, in matching these three dimensions, the model integrates performance measures and indicators, for instance, as concerns the economic-financial and social-effectiveness fields, an example of integrated indicator is the productivity of inputs (labor costs for services rendered, etc.). Similarly, for the economicfinancial and legitimacy fields, an example is compliance with the non-distribution constraint; for the social effectiveness and legitimacy fields, the correspondence between achieved results (revenues, outcomes, impact) and the social business's stated mission, involvement of workers and users/beneficiaries in decision making.

Hornsby (2012) proposes a Methodology for Impact Analysis and Assessment (MIAA), that focuses on an organization's impact. MIAA comprises two main dimensions of analysis: confidence, that looks at the financial and operational performance of an organization; and impact, that focuses on the social and environmental benefits. In addition, MIA includes a mapping stage where the profiles of organisations are classified with respect to location, sector, size etc.. To evaluate the impact of activities MIAA considers the theory of change (GSVC 2012), referring to the impact chain, that starts with a breakdown of activities, mapping what inputs it is using, how these activities produce outputs, which in turn lead to outcomes. Finally, MIAA proposes a guide for the selection of appropriate indicators, with a predefined set of metrics that could be adapted to the specific characteristics of an organization. Finally, MIAA provides a guideline concerning impact reporting as the process by which the organisation communicates its results.

The Global Social Venture Competition (GSVC) in 2012 develops the Social Impact Assessment (SIA), that is thought for social enterprises. This model suggests to quantify the value of an organization through three priority indicators, connected to the three priority results that the organization wants to achieve.

This approach is based on the theory of change to describe how the activities of a social enterprise will lead to the desired final outcome and the social impact on the value chain. The model defines three steps for the social impact evaluation. The first step consists in defining the social value chain of the organization, the second step consists in the identification of three measurable indicators of social impact more correlated with the social results and in definition of the indicators calculation methodology. The third step provides the calculation of social impact indicators and the feasible plan definition to evaluation and monitoring including the unintended consequences and / or negative of the business. To guide the identification of the indicators, the model refers to the Impact Reporting Standard \& Investment (IRIS) framework, that provides a reporting 
standard for the social and environmental performance of an organization. In details, IRIS provides a library of indicators with standard definitions that are applicable to different sectors (GIIN 2011)

Finally, Arena et al. (2014) propose a stepwise method for social enterprises to support the development of their own performance measurement system PMS. This framework is the result of an adaptation of the contingency model developed by Ebrahim and Rangan (2010) to social enterprises specificities. Moving from the original model, that is based on three elements: input, output and outcome, the authors elaborated a revised model that distinguished between management and social effectiveness (consistently with Bagnoli and Megali, 2011) and they introduce consistency variables based on the premise that resource employed, products produced and results achieved by a SE should be consistent with the mission of the organization. After defining the performance dimensions, the authors provide a guideline for supporting the design of the PMS. To this aim, the authors elaborate on the approaches of Fletcher et al. (2003) and Bourne and Walker (2005) to deal with the information needs of different stakeholders, and guide the construction of the KPIs.

\subsection{Dashboards and scorecards}

The third group of models includes dashboards and scorecards aimed to identify a set of indicators and metrics to cover different performance dimensions, that are considered representative of the results of the social business organization. These models generally refer to the objectives of the organization itself and define a set of indicators covering different of areas / performance dimensions.

Beside these commonalities, the proposed approaches present some peculiar characteristics, that make them somehow different from one another. First, they can be distinguished based on the criteria used to define the performance dimensions and to select the KPIs within each area. On the one hand, some models rely on the social and economic goals of the organization and articulate the performance dimensions accordingly (defining monetary metrics or not), other models embrace a stakeholder perspective and articulate the performance dimensions based on stakeholders' priorities. A second element of differentiation refers to the inclusion of a guideline to drive the process of selection of the performance dimensions and the KPIs. In other words, some of the analysed models are configured as a step-wise approach aimed to support the development of a performance measurement system for social businesses. Finally, the latter element of differentiation refers to the integration of the dashboard with a synthetic measure to "sum up" the overall social impact.

The first group of contributions includes some modification of the balanced scorecard proposed by Kaplan and Norton in 1996, in order to make the original model more adherent to the social business paradigm (Kaplan 2001; Moore 2003; Somers 2005; Bull 2007). These models generally result in changes of the scorecard dimensions, and integration of further performance areas, however, without a significant shift in 
the unpinning logic of the balanced scorecard - i.e. deploying the strategic objective of an organization into operational objectives in order to capture how value is created (Brignall 2003).

Kaplan proposes an adaptation of the balanced scorecard model for not for profit organizations. Kaplan starts from the consideration that, for these organizations, the agency's mission represents the rationale for their existence and put it at the center of the scorecard model (Kaplan 2001). Then, since the realization of the mission is characterized by a time lag, the measures in the four main perspectives of the Balanced Scorecard provide the short- to intermediate-term targets and feedback. In this way, the model seeks to bridge the gap between vague mission and strategy statements and day-to-day operational actions, shifting the attention of a not for profit organization from programs and initiatives to their results and outcomes.

Somers (2005) introduces three main changes to the original balanced scorecard model to adapt it to the needs of a social enterprise. First, he adds an additional layer, introducing social goals above the financial perspective; second, he broadens the financial perspective to focus on sustainability; third, the customer perspective is widened to capture a larger number of stakeholder groups.

Lastly, Bull (2007), again adapting the model to the context of social enterprises, partially modifies the original perspectives into multi-bottom line; stakeholders' environment; internal activities (related to structure, communication, quality...), and learning organization (dealing with training and knowledge management).

In this stream of references, is also included Moore (2003) model, who proposes the Public Value Score Card as an adaptation of original balance scorecard for not for profit organizations, as a mean to capture the specificities of not for profit organizations. This model is graphically represented by a "strategic triangle", that directs the attention of decision makers to three aspects that are highly critical to develop and implement an entity's strategy. The first point of the triangle, the value circle, focuses the attention on what constitutes the ultimate value the organization seeks to produce. The second point of the triangle, the legitimacy and support circle, focuses attention on "customers" that author described as "third party payers" including under this label both those customers who pay for the service, or benefit from it, and those who cover some portion of the costs i.e. donors and government. The third point of the triangle focuses the attention on the "operational capacity", that aims to explain whether an enterprise has the ability to achieve the desired goals.

This set of models captures the social, economic and financial dimension and support the definition of related KPIs. However, they provide a static framework, without an explicit connection to the whole value chain (McLoughlin et al. 2009).

The second group of contributions includes models that embrace a stakeholder perspective to define the performance dimensions and to select the indicators and metrics (Simmons 2003; Bassi 2011). 
Bassi (2011) elaborates a measurement tool for nonprofit organizations called Social Added Value Evaluation System that focuses on the participative nature of these organizations. He identifies the contribution of a not for profit organization in the production of relational value and creation of social capital. In particular, the system distinguishes between Economic and Cultural and Political Added Value, which together form the Total Societal Added Value that a third sector organization conveys to society. For each dimension, the author identifies some sub-dimensions and observable elements. For instance, the capacity to produce good relationships is described as the degree of "internal relational capacity", i.e. the frequency among internal stakeholders and the intensity (strategic importance) of these relationships; "external relational capacity", i.e. the frequency of relationships with the external stakeholders; and intensity (strategic importance) of this relationship. Then, the author identifies seven KPIs for the internal relational capacity and measures the other aspect mainly through a questionnaire aimed to detect the extent and importance of the network of relationships the organizations are involved.

Simmons (2003) focuses on the stakeholders' perspective as a key to develop a performance management system, basing his model on the assumption that effective governance must incorporates the views of different stakeholders in the decision making process. Hence, the model proposed by Simmons relies on the use of different stakeholders' perspectives to determine legitimacy and priority of different business activities / choices. To this aim, the stakeholder analysis is used to determine the relevance of different aspects that should be measured and the performance management system is seen as a "negotiated outcome" among stakeholders. This view raises the critical issue of how to achieve stakeholder consensus on different KPIs and relationships among them, and both models don't focus on the monetary metrics.

The third group of contributions includes those models that are configured as a guideline to support the identification of the performance dimensions and the related KPIs. These models generally provide both a conceptual framework and a practical approach to define the indicators, defining a sequence of steps to tailor the KPIs to the specific characteristics of social business and the informative needs of managers (DTA 2008; McLoughlin et al. 2009)

The Fit for Purpose model has been proposed by the Development Trusts Association in 2008, as a diagnostic tool to help a new or developing social enterprise to assess its strengths and weaknesses. The tool consists of five sections: governance, enterprise and business planning, financial management, partnership working and policies and procedures. For each section, there is set of up to seven KPIs; and for each KPI a guideline is provided to better specify the indicator and assess it according to a three-point rating scale (Development Trusts Association 2008).

McLoughlin et al. (2009) propose a guideline for social impact measurement of social enterprises (SEs), that is labelled SIMPLE, that stands for Social Impact for Local Economy. The Simple model combines elements of 
competitive analysis with the development of a performance measurement model, based on a five-steps approach. These steps help SE managers to conceptualize the impact problem; identify and prioritize impacts for measurement; develop appropriate impact measures; report impacts and integrate the results in management decision making and the culture of the organization. Furthermore, this model provides some criteria for defining a set of indicators to measure the impact produced by the social business organization, here labelled Key Impact Indicators.

Finally, Yang, Rong-Hwa, and Yun-Chen (2014) propose the Performance Assessment Model for Social Enterprise. This is a hierarchical model articulated along three levels. At the first level, three performance dimensions are identified: essence of social enterprise, social impact, business operations. At the second level, each dimension is further articulated into more specific areas, to whom is associated a set of assessment factors or KPIs (third level). The essence of social enterprise is further articulated into two areas, that are the social mission and the social entrepreneur. The social mission comprises four assessment factors: having a clear social mission, satisfactory correlation between social mission and operation, support of social mission by stakeholders, understanding of the social mission by members. The social entrepreneur is divided into three assessment factors: cognition degree of social mission, transforming social mission into a clear goal of social enterprise, ability to achieve a social mission. Similarly, social impact is divided into two areas: social contribution with six assessment factors (e.g. mitigation of social problems, creating positive community benefits), and social outcome with four assessment factors (e.g. creating or improving social products, creative value of innovative value). Business operations are further disaggregated into three areas: the firm survival that comprises five assessment factors (e.g. stability of resource supply, ability to use and integrate resources); the social relationship that comprises four factors (e.g. scope of social networks, ability to promote social mission), and the future potential that comprises six factors (e.g. ability to afford products and services continuously and maintaining good relationships with stakeholders). The relationship among the dimensions, areas and assessment factors is a network structure, for which the model defines the relationships between different factors and the relative weights.

The last model is characterized by the integration of the dashboard approach with a synthetic indicator (Meadows and Pike 2000). In this work, the authors identify three dimensions: Business Model, Financial Return, Organization Development, to whom they associate a set of KPIs that are interrelated and that reflect a coherent strategy from different stakeholders' point of view. Then a synthetic indicator, the SROI (see section 4.1 for a discussion of this indicator) is proposed to capture the value of the benefits that accrue to a wider constituency as a consequence of the existence and interventions of a particular social enterprise.

\section{Discussion and conclusion}


This paper starts from the idea that the lack of shared and recognized indicators and metrics represents a relevant obstacle to the growth of the social business sector since it limits the ability of these organizations of ensuring transparency and accountability (Nicholls 2009), attracting investors (Wilston 2014; Saltuk et al. 2014), mobilizing resources (Plotnieks 2014) monitoring business operations (Arena, Azzone, and Bengo 2014) and managing the balance of power among the actors considering their different objectives (EC 2014). Several authors, recognizing the importance of indicators and metrics to foster the growth of the social business sector, have proposed different models, characterized by different inherent features, that can be broadly grouped into three main categories: synthetic indicators, process based approaches and dashboards and scorecards. Hence, as follows, the research first discusses how these models answer to the interests of the key stakeholders of the social business sector, identifying the strengths and weaknesses of each approach. Then, it draws some concluding remarks, moving from a single stakeholder view, to the overall social business ecosystem.

Starting with the first issue, the paper highlights, for each stakeholder, his informative needs and the models that appear more suitable to respond to them. The investors, for instance, are interested in understanding the potentialities of different funding opportunities to decide who / what they want to finance. From this perspective, models that propose synthetic indicators, such as SROI, allow to compare the results of different organizations. On the other hand, grant-makers need to achieve a more comprehensive view of how a social business organization operates. In this case, models that are more complete can better respond to the funder's need of assessing the social impact produced. The Gamma Model (Grabenwarter and Liechtenstein 2011), for example, goes into this direction by complementing a synthetic metric with different impact performance indicators and impact investment performance indicators.

Policy makers, as already discussed, could play different roles with respect to social business organizations, since they could act as funders, contractors or lawmaker. Accordingly, their informative needs can change significantly. In the first case, they informative needs and the related indicators are aligned with those of the grant-makers, since, in this case, they are interesting in understanding the social impact produced by their investments. When they act as contractors, they aim to control service performance more in details, which calls for some disaggregated measures, that can be obtained through process based approaches. Finally, when they act as a policy maker, for instance to redefine different aspects of the legal framework or making choices about priorities in the public spending allocation, they need a complete picture of the value chain and the impacts determined in its different stages. From this perspective, process-based approaches and synthetic metrics could serve these requirements better.

Finally, decision makers within social business organizations have to monitor a comprehensive set of parameters, in order to achieve an overall picture of the organization's performance. From this perspective, dashboards and process-based models appear to be most suitable to answer to this stakeholder's interests. 
Dashboards and scorecards models, as previously highlighted, try and adapt the original Kaplan and Norton's Balanced Scorecard to the characteristics of the social business (Kaplan 2001; Moore 2003; Somers 2005; Bull 2007). However, these models do not propose a set of indicators, but provide a framework to develop it. Hence, they could be integrated with some standard frameworks that provide extensive examples of indicators and metrics, as Development Trusts Association (2008), and McLoughlinet al. 2009 and Yang and Lee (2014). On the other hand, a sound alternative / integration compared to dashboards is represented by process based models, that provide a picture process of the "production" of a social service articulating the analysis of social business performances in inputs-outputs-outcomes and impacts. Similarly to dashboards, they should be integrated with standard frameworks (Hornsby 2012; GSVC 2012; Arena et al. 2014).

These considerations, however, do not take into account at all the complexity and dynamism of the relationships that characterize the social business ecosystem. The new configurations that are currently emerging in the social business sector, in fact, rely on the establishment of partnerships and collaborative relationships among the above actors, that are pushed by new financial supply chains (EU 2014, Wilston 2014). Since these actors play a different role in the financial supply chain, some trade-off emerge and are reflected in the specific interests of each of these players. For example, considering the case of a project where payments to the investors are based on the social changes generated (as in the case of social impact bonds), there could be a complex pattern of interests. Policy makers, in fact, could focus on governmental cost savings and social impact generated for the community, investors could focus on financial returns and decision makers could focus on monetizable societal changes.

This problem is further amplified by the progressive broadening of the actors involved in the social business ecosystem, in particular in connection to the social impact investment market (Bugg-Levine and Emerson 2011) that includes social ventures, intermediaries and impact investors. These new actors are carriers of a new "incentive system" that is strongly informed by the emerging of new financing opportunities, further stretching the above trade-offs. In this new scenario, the measurement problem moves from a technical sphere, related to what indicators, what metrics are more suitable for each player to the governance sphere, where metrics and indicators are influenced, and in turns could influence, the balance of power among different actors.

As highlighted above, the measurement infrastructure in the social business sector is still in its infancy, hence it is likely to be informed by the actors that will be able to become more influential in the specific context. For instance, if in the emerging financial supply chain, traditional players of the financial markets will prevail, indicators and metrics could follow more traditional logics, focusing on financial returns. Oddly, this could determine an over-emphasis on financial results in the social business sector, at a time when many private sector organizations have been moving towards more comprehensive indicators and metrics (G8 2014). 
On the contrary, if the ecosystem will develop in a more balanced way or if social business organizations will be able to take on a leading role in setting the agenda, indicators and metrics are expected to be more focused on social impacts, maybe disregarding financial returns. At any rate, this evolution will be influenced by the evolution of the social business ecosystem, for whom at present is difficult to make a prevision, and practice variations can be expected in different fields and different countries.

Furthermore, it is worthy of mentioning that metrics and indicators could play a crucial role in influencing political bargaining processes and power relationships among different actors within an organization and, more in general, within the whole eco-system at the policy level (Brignal and Modell 2003). Measuring something provides not only the basis for managing it (Emerson 2003), but it is typically central in decisions concerning performance evaluation, resource allocation, and new policy developments (Lepoutre et al. 2013). Hence, the choice of a specific metric compared to another could lead to a larger or smaller recognition of the contribution of the social business sector itself, eventually favoring or hampering future potential developments.

From this perspective, looking at the single stakeholder is relatively not useful because he is influenced by his own interests; instead governments and policy makers at the international level should take on the responsibility of ensuring that the negotiation among different stakeholders happens in a fair context. In this light, they should define proper governance mechanisms, embracing a systemic view of the eco-system, and ensure the development of a fair measurement infrastructure. This appears particularly important in order to avoid to lose the opportunity of leveraging on social business in order to improve the provision of social services and address some of the big societal challenges that have been discussed in the beginning of the paper.

A final consideration concerns the need of fostering a cultural change, that goes beyond the introduction of indicators and metrics, in order to integrate societal impacts in the economic system. Metrics and indicators are fundamental to favor the establishment of virtuous circle whereby investors can invest (instead of donate) in a social business initiative, that in turns ensure a financial return and is committed (and locked) to create social value and determine concrete impacts. This could play a role in fostering a more equitable economic system.

This cultural change is partially taking place in terms of policies. The emphasis that the European Commission is placing upon the growth of social business and impact investing as a more effective way to answer to emerging social challenges provides evidence of the commitment of policy makers in this field. This attention is further confirmed by the recent OECD report entitled "New Investments Approaches for Addressing Social and Economic Challenges" (Wilston 2014), and by the results of the Working Group on impact measurement (under the direct supervision of the Social Impact Investment Task Force). Policy makers at different levels 
recognize a central role to the governments in creating the "right" infrastructure to strengthen new privatepublic partnership models, to scale up innovative solutions and to ensure the alignment between capital demand (social business) and capital offer (impact investing).

For ensuring this alignment, it is important that every Country, succeed in beating "the invisible heart of markets" (G8 2014), defining adequate laws to facilitate the growth of social business, implementing technical support for social enterprises and helping private sector organizations to see in the social impact dimension a strategic driver for investment allocation.

The attention of policy makers is also reflected in the evolution of practices embraced by for-profit organizations. In this field, traditional accounting frameworks have been evolving over time, creating a bridge between different accounting instruments, as in the case of new guidelines entitled "Linking GRI and IRIS" (GRI and IRIS 2014). These guidelines aim to help impact investors to make a connection between IRIS and GRI, aggregating and comparing performance in a reliable way. The relevance of this issue is confirmed by the results of a survey conducted by the GIIN and J.P. Morgan (Saltuk et al. 2014), where more than twothirds of respondents agree about the need of standardized impact metrics to foster the development of the industry.

This paper signs a potential contribution to both theory and practice. From an academic perspective, the paper analyses the state of the art literature in a systemic way, highlighting the strengths and weaknesses of different approaches and connecting them to the information needs of key stakeholders in the social business sector. Coherently with prior research in the field, the paper underlines how metrics and indicators are a fundamental factor to foster the development of the social business sector. In particular, it highlights how indicators and metrics can contribute to favor the alignment between supply and demand in the financial supply chain, in the light of a broader vision of social business ecosystem and its potential trajectories of development. For practitioners, this paper delivers a pragmatic perspective on how social impact can be evaluated and which tools can better answer to the interests of different stakeholders, considering that practitioners themselves (including investors, social entrepreneurs, policy makers) are those that are more involved in the measurement issue.

In the end, the paper discusses potential areas for future development of this research. As regards the stakeholders, it carried out a first analysis that is based on the current state of the art. Since the social business sector is under significant development, the information needs of different stakeholders and the related indicators and metrics could change following the evolution of the ecosystem and the incidence and power of these stakeholders may vary considerably between countries, parts of the social business sector or moment in time. From this perspective, future research could embrace the ecosystem perspective and address in more depths, through an empirical analysis, the role of metrics and indicators in balancing the 
powers of different actors in the social business ecosystem. Concerning this issue some aspects that appear to be particularly interesting deal with the governance system of the measurement infrastructure - for instance is a third sector agency that monitors performance in the social sector a potential solution to the measurement challenge? 


\section{References}

1. Achleitner, A.K., Heinecke, A., Noble, A., Schoning, M., and Spiess-Knalf, W. 2011. "Unlocking the Mystery, An intoduction to Social Investment". Innovations, 6 (3): 41-50.

2. Alexander, J., Brudney J.L., and Yang, K. 2010. "Introduction to the Symposium: Accountability and Performance Measurement: The Evolving Role of Nonprofits in the Hollow State". Nonprofit and Voluntary Sector Quarterly, 39 (4): 565-570.

3. Alter, K.A., 2006. "Social enterprise models and their mission and money relationships". In: A. Nicholls, ed. Social entrepreneurship: new models of sustainable social change. Oxford: Oxford University Press, 205-233.

4. Arena, M., Azzone, G., Bengo, I. 2015. "Performance Measurement for Social Enterprises". VOLUNTAS: International Journal of Voluntary and Nonprofit Organizations, 26 (2): 649-672Arksey, H., and O'Malley, L. 2005. "Scoping studies: towards a methodological framework". International journal of social research methodology, 8 (1): 19-32.

5. Auerswald, P. 2009. “Creating social value”. Stanford social innovation review, 7 (2): 51-55.

6. Austin, J., Stevenson, H., and Wei-Skillern, J. 2006. "Social and commercial entrepreneurship: Same, different, or both?". Entrepreneurship Theory and Practice, 30 (1): 1-22.

7. Bagnoli, L., and Megali, C. 2011. "Measuring Performance in Social Enterprises". Nonprofit and Voluntary Sector Quarterly, 40 (1): 149-165.

8. Bassi, A. 2011. Il valore aggiunto sociale del terzo settore. Verso un sistema di indicatori per la misurazione della performance delle imprese sociali. Milan: QuiEdit.

9. Bebbington, K.J., Gray R.H. and Owen D.L. 1999. "Seeing the wood for the trees: taking the pulse of social and environmental accounting". Accounting, Auditing and Accountability Journal, 12 (1): 47-51

10. Bebbington, J., Unerman, J. and O'Dwyer, B. (Eds.) 2014. Sustainability accounting and accountability. Routledge

11. Bebbington, J. and Gray, R. 2001. "An account of sustainability: failure, success and a reconceptualization". Critical perspectives on accounting, 12(5): 557-588.

12. Bourne, L. and Walker, D. H. T. 2005. "Visualising and Mapping Stakeholder Influence". Management Decision, 43 (5): 649-660.

13. Brignall, S. Modell, S. 2000. "An institutional perspective on performance measurement and management in the 'new public sector'". Management accounting research, 11 (3): 281-306.

14. Brinkman, H.J., De Pee, S., Sanogo, I., Subran, L., and Bloem, M.W. 2009. "High food prices and the global financial crisis have reduced access to nutritious food and worsened nutritional status and health". Journal of Nutrition, 140 (1): 153S-161S. 
15. Bugg-Levine, A., and Emerson, J. 2011. "Impact Investing, Transforming How We Make Money While Making a Difference". Innovations, 6 (3): 31-40.

16. Bull, M., and Crompton, H. 2006. Business practices in social enterprises. Social Enterprise Journal, 2 (1): $42-60$.

17. Bull, M. 2007. "Balance: the development of a social enterprise business performance analysis tool". Social Enterprise Journal, 3 (1): 49-66.

18. Carter, N., Klein, R., Day, P. 1995. How Organisations Measure Success: The Use of Performance Indicators in Government. London: Routledge.

19. Chan, H.W., Makarov, V., and Thompson, S. 2010. "Beyond the "Tradeoff": A new Analytical Framework for the Social Impact Investing Industry". Working Paper.

20. Chan, K. H. 2009. "Impact of intellectual capital on organisational performance: an empirical study of companies in the Hang Seng Index (part 1)". Learning Organization, 16 (1): 4-21.

21. Crowther, D., and Reis, C. 2011. "Social responsibility or social business?". Social Business, 1 (2): 129-148.

22. Dart, R., and Grant, S. 2004. The Social Construction of Social Enterprise. Canada: Trent University.

23. Development Trusts Association, DTA. 2008. "Fit for purpose: the Development Trusts Association healthcheck for community enterprise organisations". Accessed October 6th, 2014. http://locality.org.uk/wp-content/uploads/Fit-for-Purpose.pdf.

24. Ebrahim, A,. and Rangan, K. 2010. "The Limits of Nonprofit Impact: A Contingency Framework for Measuring Social Performance". Harvard Business School Working Paper.

25. Emerson, J., 2003. "The Blended Value Proposition: Integrating Social and Financial Returns". California management review, 45 (4): 36

26. European Commission, Enterprise and Industry, 2011. Social Economy. Accessed September 19. http://ec.europa.eu/enterprise/policies/sme/promoting-entrepreneurship/social-economy/

27. European Commission, 2014. "Proposed Approaches to Social Impact Measurement" in European Commission legislation and in practice relating to: EuSEFs and the EaSI. Accessed November $10^{\text {th }} 2014$. http://www.ec.europa.eu/internal_market/social_business/docs/expert-group/social_impact/140605sub-group-report_en.pdf.

28. Fletcher, A., Guthrie, J., Steane, P., Roos, G. and Pike, S. 2003. "Mapping stakeholder perceptions for a third sector organization". Journal of Intellectual Capital, 4 (4): 505-527.

29. Flockhart, A., 2005. "Raising the profile of social enterprises: the use of social return on investment (SROI) and investment ready tools (IRT) to bridge the financial credibility gap". Social Enterprise Journal, 1 (1): $29-42$.

30. Flynn, N. 1997. Public Sector Management. London: Prentice-Hall/Harvester Wheatsheaf.

31. Freeman, R.E. 1984. Strategic Management: A Stakeholder Approach. MA: Pitman Publishing Company. 
32. Freireich, J. and Fulton, K. 2009. Investing For Social and Environmental Impact: A Design for Catalyzing an Emerging Industry. New York: Monitor Group

33. Friedman, A.L. and Miles, S. 2002. "Developing stakeholder theory". Journal of Management Studies, 31(1): 1-21

34. Gao, S. S. and Zhang, J. J. 2006. "Stakeholder engagement, social auditing and corporate sustainability". Business Process Management Journal, 12(6): 722-740.

35. G8, Social Impact Investment Taskforce, 2014. "IMPACT INVESTMENT: The invisible heart of markets harnessing the power of entrepreneurship, innovation and capital for public good". Accessed November $10^{\text {th }}, 2014$. http://www.socialimpactinvestment.org/.

36. Glänzel, G., Schmitz, B., and Mildenberger, G. 2012. "Report on Social Finance Investment Instruments, Markets and Cultures in the EU, a deliverable of the project: "The theoretical, empirical and policy foundations for building social innovation in Europe" Brussels, European Commission, DG Research.

37. Global Social Venture Competition, GSV, 2012. "Social Impact Assessment Guidelines". Accessed September 19th, 2014. http://www.i-edu.org.cn/gsvc/download/2011 GSVC SIA Guidelines.pdf

38. Global Impact Investing Network, 2011. "Impact- based incentive structures, Aligning Fund Manager Compensation with Social and Environmental Performance". Accessed November 10th, 2014. http://www.thegiin.org/binary-data/RESOURCE/download file/000/000/332-1.pdf

39. GRI AND IRIS, 2014. "Linking GRI and IRIS: How to use the IRIS metrics in the preparation of a sustainability report based on the GRI G4 Sustainability Reporting Guidelines". Accessed February 9th, 2015. http://www.globalreporting.org/G4 and https://iris.thegiin.org

40. Grabenwarter, U., and Liechtenstein, H. 2011. "In Search of Gamma-An Unconventional Perspective on Impact Investing". IESE Business School, University of Navarra.

41. Gray, R.H., Dey, C., Owen, D., Evans, R. and Zade S. 1997. "Struggling with the praxis of social accounting: stakeholders, accountability, audits and procedures". Accounting, Auditing and Accountability Journal, 10(3): 325-364.

42. Gray, R.H. 2000. "Current developments and trends in social and environmental auditing, reporting and attestation: a review and comment". International Journal of Auditing, 4 (3): 247-268.

43. Gray, R. 2001. "Thirty years of social accounting, reporting and auditing: what (if anything) have we learnt?". Business ethics: A European review, 10(1): 9-15.

44. Gray, R.H. 2002. "The social accounting project and Accounting, Organizations and Society: privileging engagement, imagination, new accountings and pragmatism over critique?". Accounting, Organizations and Society, 27(7): 687-708.

45. Guba, E.S. and Lincoln, Y.S. 1989. Fourth Generation Evaluation. Sage Publications, Newbury Park, CA

46. Hebb, T. 2013. “Impact Investing and Responsible Investing: What Does It Mean?". Journal of Sustainable Finance and Investment, 3 (2): 71-74. 
47. Heinrich, C.J. 2002. "Outcomes-Based Performance Management in the Public Sector: Implications for Government Accountability and Effectiveness". Public Administration Review, 62 (6): 712-725.

48. Herman, R. D. and Renz, D. O. 1997. "Multiple constituencies and the social construction of nonprofit organization effectiveness". Nonprofit and Voluntary Sector Quarterly, 26 (2): 185-206.

49. Hornsby, A, 2012. "The good analyst, Impact Measurement and Analysis in the Social-Purpose Universe". Investing for Good. Accessed September 19 th, 2014. http://www.goodanalyst.com/fileadmin/ifg users/pdf/thegoodanalyst.pdf

50. Hornsby, A., Blumberg, G. 2013. "The Good Investor A BOOK OF BEST IMPACT PRACTICE. Investing for Good. Accessed September 19th, 2014. http://www.goodinvestor.co.uk/download-the-good-investorpdf/

51. Hyndman, N., and McMahon, D. 2011. "The hand of government in shaping accounting and reporting in the UK charity sector". Public Money \& Management, 31 (3): 167-174.

52. Jansson, M., and Biel, A. 2011. "Motives to Engage in sustainable Investment: A Comparison Between Institutional and Private Investors". Sustainable Development, 19 (2): 135-142.

53. Jackson, E.T. 2013. "Interrogating the theory of change: evaluating impact investing where it matters most". Journal of Sustainable Finance \& Investment, 3 (2): 95-110.

54. Kaplan, R.S., and Norton, D.P. 2001b. "Transforming the Balanced Scorecard from performance measurement to strategic management". Part II. Accounting Horizons, 15 (2): 147-160.

55. Karamchandani, A., Kubzansky, M., and Frandano, P. 2009. "Emerging Markets, Emerging Models: Market Based Solutions to the Challenges of Global Poverty" Monitor Group. Accessed November 3rd , 2014.http://www.monitor.com/Portals/0/MonitorContent/documents/Monitor Emerging Markets NEDS $03 \quad 25$ 09.pdf

56. Karanikolos, M., Mladovsky, P., Cylus, J., Thomson, S., Basu, S., Stuckler, D., Mackenbach, and J.P. McKee, M. 2013. "Financial crisis, austerity, and health in Europe". The Lancet, 381 (9874): 1323-1331.

57. Kendall, J., and Knapp, M. 2000. "Measuring the Performance of Voluntary Organisations". Public Management, 2 (1): 105-132.

58. Korosec, R. L., and Berman, E. M. 2006. "Municipal support for social entrepreneurship". Public Administration Review, 66 (3): 448-462.

59. Lawlor, E. 2009. "Social return on investments: an approach to avoiding false economies". Working Paper. TSRC, Birmingham. Accessed September 10th, 2014. http://eprints.mdx.ac.uk/7104/

60. Lyon, F., Arvidson, M., Etherington, D. and Vickers, I. 2010. "Social impact measurement (SIM) experiences and Future directions for third sector organisations in the East of England". Report for EEDA. Accessed October 10th, 2014. http:// www.the-guild.co.uk.

61. Marks, L., and Hunter, D. J. 2007. Social Enterprises and the NHS: changing patterns of ownership and accountability. London: Unison. 
62. Mathews, M.R. 1997. "Twenty-five years of social and environmental accounting research". Accounting, Auditing \& Accountability Journal, 10 (4): 481-531.

63. Mathews, R. 2004. “Developing a matrix approach to categorise the social and environmental accounting research literature". Qualitative Research in Accounting \& Management, 1 (1): 30-45.

64. McLoughlin, J., Kaminski, J., Sodgar, B., Khan, S., Harris, R., Arnaudo, G., and Mc Brearty, S. 2009. "A strategic approach to social impact measurement of social enterprises. The SIMPLE methodology". Social Enterprise Journal, 5 (2): 154-178.

65. Meadows, M., and Pike, M. 2010. "Performance management for social enterprises". Systemic practice and action research, 23 (2): 127-141.

66. Mook, L., \& Quarter, J. 2006. "Accounting for the social economy: The socioeconomic impact statement". Annals of Public and Cooperative Economics, 77 (2): 247-269.

67. Moore, MH. 2003. "The public value scorecard: a rejoinder and an alternative to strategic performance measurement and management in non-profit organizations". Hauser Center for Nonprofit Organizations Working Paper, 18.

68. New Economics Foundation (NEF), 2007. "Measuring Real Value: A DIY Guide to Social Return on Investment". Accessed November 3rd, 2014. http://www.neweconomics.org/

69. Nicholls, A. 2010a. "Institutionalizing social entrepreneurship in regulatory space: Reporting and disclosure by community interest companies". Accounting, Organizations and Society, 35 (4): 394-415.

70. Nicholls, A. 2010b. "The legitimacy of social entrepreneurship: reflexive isomorphism in a preparadigmatic field". Entrepreneurship theory and practice, 34 (4): 611-633.

71. Nicholls, A. 2009. "We do good things, don't we?: 'Blended value accounting' in social entrepreneurship". Accounting Organizations and Society, 34 (6-7): 755-769.

72. O'Dwyer, B. 2005. "Stakeholder democracy: challenges and contributions from social accounting". Business Ethics: A European Review, 14(1): 28-41.

73. OECD, 2014. "General assessment of the macroeconomic situation". Economic Outlook, no. 2. Accessed October 6th 2014. http://www.oecd.org/eco/outlook/General-assessment-of-the-macroeconomicsituation.pdf

74. Olsen, S., and Galimidi. 2008. "Catalog of approaches to impact measurement, Assessing social impact in private ventures". Social Venture Technology Group. Accessed November 3rd, 2014. http://www.midot.org.il/Sites/midot/content/Flash/CATALOG\%200F\%20APPROACHES\%20TO\%20IMP

\section{ACT\%20MEASUREMENT.pdf}

75. Ormiston, J., and Seymour, R. 2011. "Understanding value creation in social entrepreneurship: The importance of aligning mission, strategy and impact measurement". Journal of social entrepreneurship, $2(2): 125-150$. 
76. Owen, D.L. and Swift, T. 2001. "Social accounting, reporting and auditing: beyond the rhetoric?" Business Ethics: A European Review, 10 (1): 4-8.

77. Paton, R. 2003. Managing and Measuring Social Enterprises. London, Sage.

78. Patton, M. Q. 2003. Utilization-focused evaluation . Springer, Netherlands.

79. Peredo, A. M., and McLean, M. 2006. "Social entrepreneurship: A critical review of the concept". Journal of world business, 41 (1): 56-65.

80. Perrin, B. 1998. "Effective Use and Misuse of Performance Measurement". American Journal of Evaluation, 19 (3): 367-379.

81. Plotnieks, D. 2014. "Mechanisms Fostering Social Entrepreneurship as Potential Instruments for Economic Development: The Eastern Partnership Perspective". Baltic Journal of European Studies, 4 (2): 34-49.

82. Preston, L.E. and Donaldson, T. 1999. "Stakeholder management and organizational wealth", Academy of Management Review, 24 (4): 619.

83. Reinhart, C.M., and Rogoff, K.S. 2010. "From Financial Crash to Debt Crisis". NBER Working Paper Series, n. 15795.

84. Richmond, B. J., Mook, L., and Quarter J. 2003. "Social accounting for nonprofits: Two models". Nonprofit management and Leadership, 13 (4): 308-324.

85. Rose, A., Lawton, A. 1999. Public Services Management. London, Prentice Hall.

86. Rotheroe, N. and Richards, A. 2007. "Social return on investment and social enterprise: transparent accountability for sustainable development". Social Enterprise Journal 3 (1): 31-48

87. Sacks, J. 2002. The Money Trail: Measuring your impact on the local economy using LM3. London: New Economics Foundation.

88. Saltuk, Y., Idrissi, A., Bouri, A., Mudaliar, A., and Schiff, H. 2014. "Spotlight on the market: The impact investor survey". Global Social Finance, JP Morgan and the Global Impact Investing. London: Network.

89. Santos, F. M. 2012. "A positive theory of social entrepreneurship". Journal of business ethics, 111 (3): 335-351.

90. SEC 2011. "Creating a favourable climate for social enterprises, key stakeholders in the social economy and innovation". Communication from the commission to the European Parliament, the Council, the European economic and social committee and the committee of the regions. Social Business Initiative. Accessed November 10th, 2014. http://www.europarl.europa.eu/.

91. Seelos, C., and Mair, J. 2005. "Social entrepreneurship: Creating new business models to serve the poor". Business Horizons, 48 (3): 241-246

92. Sefton, T. 2000. "Getting less for more: economic evaluation in the social welfare field". LSE STICERD Research Paper, CASE044

93. Sethi, S. P. 2005. "Investing in socially responsible companies is a must for public pension funds-because there is no better alternative". Journal of Business Ethics, 56 (2): 99-129. 
94. Sgherri, S., and Zoli, E. 2009. "Euro Area Sovereign Risk During the Crisis". IMF Working Paper, WP/09/222.

95. Simmons, J. 2003. "Balancing performance, accountability and equity in stakeholder relationships: towards more socially responsible HR practice". Corporate Social Responsibility and Environmental Management, 10 (3): 129-140.

96. Sinkovics, N., Sinkovics, R. R., and Yamin, M. 2014. "The role of social value creation in business model formulation at the bottom of the pyramid-Implications for MNEs?". International Business Review, 23 (4): 692-707

97. Smith, P. 1995. "Performance indicators and outcomes in the public sector". Public Money \& Management, 15 (4): 13-16.

98. Somers, A.B. 2005. "Shaping the Balanced Scorecard for use in UK social enterprises". Social Enterprise Journal, 1 (1): 43-57.

99. Stone, C.D. 1975. Where the Law Ends. Harper \& Row, New York, NY.

100. Thomson, I. and Bebbington, J. 2005. "Social and environmental reporting in the UK: a pedagogic evaluation". Critical Perspectives on Accounting, 16 (5): 507-533.

101. Vis, B., Kersbergen, K., and Hylands, T. 2011. "To What Extent Did the Financial Crisis Intensify the Pressure to Reform the Welfare State?". Social Policy \& Administration, 45 (4): 338-353.

102. Wendt, A. 1999. Social Theory of International Politics. Cambridge University Press, Cambridge

103. Wilson, F., and Post, E.J. 2013. "Business models for people, planet \& profits": exploring the phenomena of social business, a market-based approach to social value creation". Small Business Economics, 40 (3): 715-737.

104. Wilson, K. E. 2014. "New Investment Approaches for Addressing Social and Economic Challenges". OECD Science, Technology and Industry Policy, Papers No. 15, OECD Publishing.

105. World Bank, 2003. World Development Report 2004. “Making Services Work for Poor People". World Bank. Accessed September 19th, 2014. https://openknowledge.worldbank.org/handle/10986/5986 License: CC BY 3.0 IGO.

106. Yang,L., Rong-Hwa, H., and Yun-Chen L. 2012. "Building a performance assessment model for social enterprises-views on social value creation". Science Journal of Business and Management, 2 (1): 1-9.

107. Yunus, M., Moingeon, B., and Lehmann-Ortega, L. 2010. "Building Social Business Models: Lessons from the Grameen Experience". Long Range Planning, 43 (2-3): 308-325.

108. Yunus, M. 2007. Creating a world without poverty: Social business and the future of capitalism. New York: PublicAffairs. 


\begin{tabular}{|l|l|}
\hline \multicolumn{1}{|c|}{ Steps of the scoping review } & \multicolumn{1}{|c|}{ How the step was performed } \\
\hline Identifying questions & $\begin{array}{l}\text { The key questions we attempted to answer are: Which indicators } \\
\text { and metrics can be used in social business? What approaches can } \\
\text { be used to support the identification of indicators and metrics? Do } \\
\text { these approaches really respond to objectives and information } \\
\text { needs of different stakeholders?. }\end{array}$ \\
\hline Identifying relevant literature & $\begin{array}{l}\text { We adopted a strategy that involved searching for research } \\
\text { evidence via different sources: electronic databases, hand- } \\
\text { searching of key journals, existing networks, relevant organisations } \\
\text { and conferences. }\end{array}$ \\
\hline Selecting the literature & $\begin{array}{l}\text { We included papers that propose indicators, conceptual } \\
\text { frameworks and guidelines for selecting indicators and metrics in } \\
\text { social business (considering not for profit, social enterprises, } \\
\text { impact finance initiatives). A preliminary selection was based on } \\
\text { the title and abstract of the papers. }\end{array}$ \\
\hline Collating, summarizing & $\begin{array}{l}\text { Materials collected was charted according to three main type of } \\
\text { approach: synthetic indicators, process based models, and } \\
\text { dashboards and scorecards. }\end{array}$ \\
\hline Charting the data & $\begin{array}{l}\text { The results of the review are presented in section four according to } \\
\text { the three categories outlined above. }\end{array}$ \\
\hline
\end{tabular}

Table 1 - The scoping review 


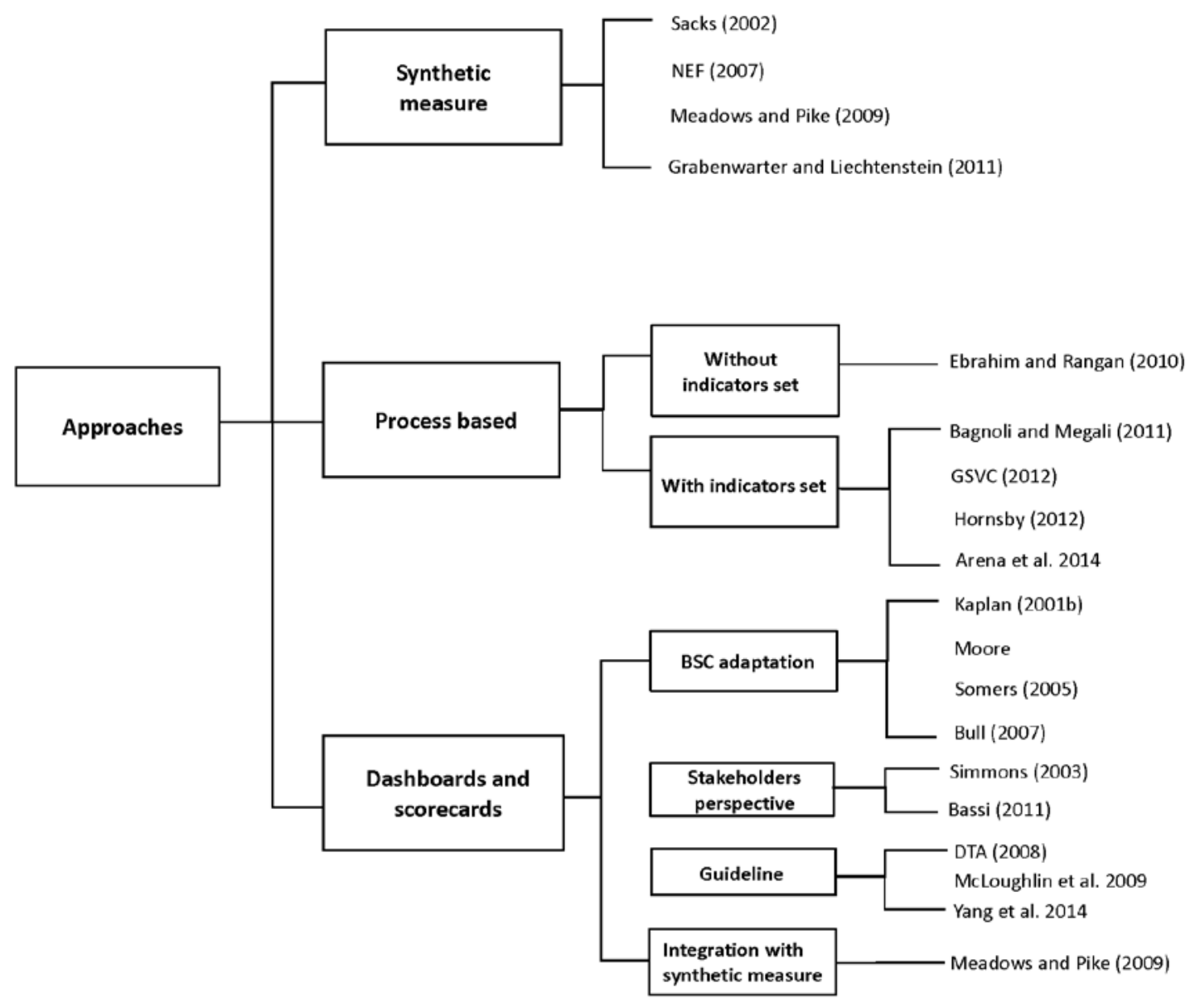

Figure 1 - Approaches used to define indicators and metrics for social business 